\title{
Plan needed to capitalize on robots, Al in health care
}

\author{
— Cite as: CMAJ 2017 February 27;189:E329-30. doi: 10.1503/cmaj.1095395
}

anada needs a national strategy for keeping ahead of rapid advances in the use of robotics, artificial intelligence (AI) and 3D printing in health care, experts told the Senate Committee on Social Affairs, Science and Technology.

In a Feb. 2 hearing, they described a near-future where smart phones and wearable tech will continuously collect and analyze health data to predict and diagnose diseases with greater accuracy; where hospitals will be staffed by robotic surgeons, pharmacists and orderlies; where organs and medicines will be printed to order; and where drones and telemedicine will bring medical supplies and expertise to patients' bedsides, however remote.

The technologies to make this sciencefiction vision a reality already exist in labs and pilots around the world, said Abishur Prakash, a geopolitical futurist at Toronto's Center for Innovating the Future. Expanding their development and use could slash health care costs while improving outcomes and access. But Canada doesn't have a plan for balancing these benefits against inevitable "automation blowback."

"Studies are showing that $42 \%$ of Canadian jobs are at risk of being automated," Prakash said. This could have seismic effects on population health. "Will people become more depressed? Will they stop working out and eating healthy? Will they drink more?"

Dr. Bertalan Mesko, a Hungarian medical futurist, said research ethics committees and government have important roles to play in setting checks and ba-

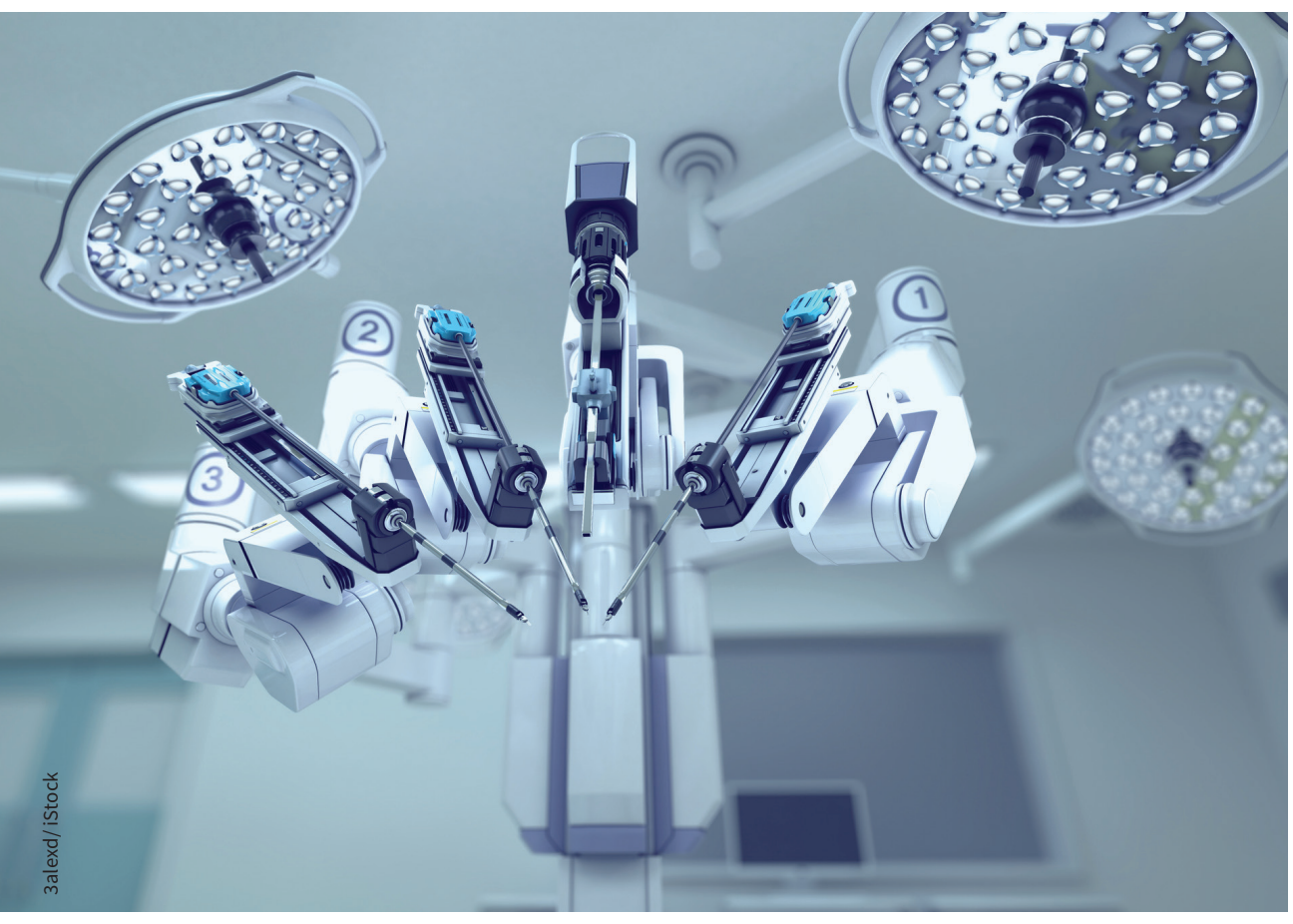

Canada isn't prepared for the knock-on effects of increasing automation in health care and society at large. lances on new technologies. However, he also cautioned that "technology will keep developing no matter what we do," so smart regulations should focus on preparing patients and physicians to ride the tide of change. "What we are witnessing today isn't a technological revolution but a cultural one."

Mesko and Prakash argued that Canada should follow the lead of countries like China and Japan which have developed national strategies for becoming robotic superpowers. A Canadian strategy could foster an "ecosystem in health care" that makes the most of physicians' empathy, creativity and judgment, while automating repetitive tasks, data analysis, epidemiology and collection of medical information, said Mesko.

Prakash said Canada's plan should also look beyond the health sector to take into account the social, economic and foreign policy impacts of automation. "You have to prepare for what's coming and if you don't prepare, then you're going to be left on the side."

Physicians will likely see their roles transformed or reduced by more sophisticated computers, he said. "Al is capable of diagnosing things in a way we haven't seen before." One study used Al to identify 17 diseases from a breath test with $86 \%$ accuracy. IBM's Watson supercomputer is claimed to diagnose lung cancer with greater accuracy than doctors, and makes evidence-based decisions in minutes from scanning thousands of studies that a human would need decades to review. As more phone apps harness these diagnostic powers, "people won't be visiting doctors as much," Prakash said.

Advances in automation outside the health sector could also have disruptive effects on care, he added. For example, self- 
driving cars are expected to reduce accidents dramatically. "One in five organ donations come from car accidents; if accidents decline, organ donations decline." The role of government in health care may also change if unemployment from automation cuts into tax revenues, Prakash said.

Senators expressed alarm about the lack of overarching ethics guiding the development of these technologies. Sena- tor Kelvin Ogilvie noted that the committee "searched for ethicists in this area but there are none."

Senator Tony Dean also pointed out that robotics, Al and 3D printing support a "vastly more distributed approach to health care that will see a much broader role for the private sector." This may only improve access to personalized, home-based care for "those who can afford it," he said.
Prakash agreed that "there is a huge void in the industry" in terms of ethical oversight. Even robots and Al have "inherent biases" based on how they are programmed. "That means the burden of responsibility lies with engineers and programmers and who gives them the right?"

Lauren Vogel, CMAJ 